\title{
A geophysical analysis of hydro-geomorphic controls within a headwater wetland in a granitic landscape, through ERI and IP
}

\author{
E. S. Riddell ${ }^{1}$, S. A. Lorentz ${ }^{1}$, and D. C. Kotze ${ }^{2}$ \\ ${ }^{1}$ School of Bioresources Engineering and Environmental Hydrology, University of KwaZulu-Natal, Private Bag X01, \\ Scottsville, Pietermaritzburg, 3209, South Africa \\ ${ }^{2}$ Centre for Environment and Development, University of KwaZulu-Natal, Private Bag X01, Scottsville, Pietermaritzburg, \\ 3209, South Africa
}

Received: 12 March 2010 - Published in Hydrol. Earth Syst. Sci. Discuss.: 22 March 2010

Revised: 13 August 2010 - Accepted: 20 August 2010 - Published: 31 August 2010

\begin{abstract}
Wetlands are undergoing considerable degradation in South Africa. As interventions are often technical and costly, there is a requirement to develop conceptual process models for these wetland systems so that rehabilitation attempts will be successful. This paper presents an approach using the geophysical methods of Electrical Resistivity Imaging (ERI) and Induced Polarization (IP) to delineate sub-surface hydro-geomorphic controls that maintain equilibrium disconnectivity of wetland-catchment processes, which through gully erosion are increasing the catchments connectivity through loss of water and sediment. The findings presented here give insight into the geomorphic processes that maintain the wetland in an un-degraded state, this allows for the development of a conceptual model outlining the wetland forming processes. The analysis suggests that sub-surface clay-plugs, within an otherwise sandy substrate are created by illuviation of clays from the surrounding hillslopes particularly at zones of valley confinement.
\end{abstract}

\section{Introduction}

Wetlands in southern Africa as in most parts of the world continue to be vulnerable to anthropogenic pressures and climatic shifts which influence the hydrological and geomorphologic processes that otherwise maintain the equilibrium

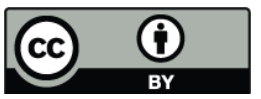

Correspondence to: E. S. Riddell (edriddell@gmail.com) of the wetlands dynamic state. Consequently many wetlands are continually undergoing degradation. In recent years the drive has been to determine the wetlands structure and function within the broader landscape in order for rehabilitation of these degraded systems to be sustainable. In the interests of ecosystem integrity significant emphasis is now placed on understanding a wetlands hydro-geomorphic setting to ensure the success of such intervention, whereby the causes of wetland degradation rather than the symptom are incorporated into the rehabilitation planning (Tooth and McCarthy, 2007). In other words rehabilitation must be sympathetic to and not in conflict with the natural dynamic of the wetland or river system, and hence seek to maintain those processes that govern the systems water balance (Ellery et al., 2008). It is within this context that a detailed hydrological monitoring of a technical rehabilitation effort was undertaken within a headwater wetland catchment of the Sand River in northeastern South Africa, as part of a river rehabilitation program. These headwater sub-catchments are characterized by channeled and un-channeled valley bottom wetlands with a sandy soil matrix derived from the surrounding granitic geology. It was postulated that zones of finer sediment within this matrix controlled the lateral movement of water within these wetlands prior to their degradation, and these fine sediment zones are being removed through extensive gully erosion (Pollard et al., 2005). It is the stabilization of these gullies that are the focus of technical rehabilitation efforts. Descriptions of the hydrodynamic behaviours of the wetland phreatic surfaces prior to rehabilitation interventions revealed stark differences in event driven responses

Published by Copernicus Publications on behalf of the European Geosciences Union. 
either side of a suspected clay-plug in this wetland (Riddell et al., 2007). Clay-plugs are distinct zones of fine particles in an environment that is otherwise dominated by coarse particles, and due to the lower hydraulic conductivities of this medium, they are thought to exert significant controls on lateral subsurface flows in the wetlands of the Sand River catchment. It is the identification and examination of these sub-surface structures that are presented here.

This paper presents results of geophysical interpretation of the wetlands hydro-geomorphology using Electrical Resistivity Imaging (ERI) in both 2 dimensional form (2-D) during scoping surveys and a more detailed examination of hydrogeomorphic controls in 3 dimensional form (3-D) using ERI and Induced Polarization (IP) techniques. The 2-D surveys using ERI only were deployed at various times during the hydrological characterization of this catchment (2005-2009) and were used in a reconnaissance fashion to assist in the interpretation of hydrological processes. 2-D readings were conducted as single onetime surveys, however it was preferred to conduct them during the late winter (dry season, March-October/November) period, as soil moisture contents were at their minimum and therefore variability in electrical resistivity measurements were assumed to have been minimally affected.

The 3-D surveys using both ERI and IP were used to examine the clay-plug distribution and develop concepts regarding their geomorphic evolution. The geophysical techniques used here have their roots in the mineral prospecting and other geotechnical investigations (Lowrie, 2007) but are now being increasingly used by the earth science fraternity involved in water resources management and geomorphology studies, whose recognition of their utility has been widely acknowledged (Robinson et al., 2008; Dahlin, 1996). ERI for instance has successfully been used in the interpretation of hillslope flow pathways in research catchments in South Africa (Uhlenbrook et al., 2005), examining permafrost distribution in peri-glacial mountain environments in Europe (Kneisel, 2006) and weathering and erosion processes on lateritic plateaus of south Pacific islands (Beauvais et al., 2007). ERI has been praised as a valuable, cost-effective and nonintrusive tool for conducting reconnaissance surveys in geomorphological investigations (Smith and Sjogren, 2006). Whilst IP has not received as much attention as resistivity methods, it was demonstrated by Slater and Lesmes (2002) to reveal valuable data on clay-free and clay-rich stratifications in 1-D and 2-D field surveys. Meanwhile, IP is now proving important as a complementary tool to resistivity mapping, for instance to delineate sub-surface materials in low resistivity clay rich environments it has shown success such as slope instability studies in Switzerland (Marescot et al., 2008). Interestingly it has also showed promise in mapping the stratigraphy of peatlands in the north-eastern United States, particularly the high chargeability of partially decomposed organic matter found therein (Slater and Reeve, 2002).
The basis of ERI surveying is the induction of an electrical current by an array of current electrodes inserted into the ground surface, with a sequence of potential electrodes receiving the electrical signal. Hence the measurements of electrical potential at the surface are dependent on the electrical resistance of sub-surface materials, expressed in ohm metres $(\Omega \mathrm{m})$, which vary according to sub-surface strata, as a result of their inherent pore size distribution, variations in water content and degree of salinity (Loke, 1999). The collation of this sub-surface resistivity distribution is facilitated by computerized devices known as switching units that control the sequence of pairs of current and potential electrodes, known as the quadripole. Variations in the position and sequence of current and potential electrodes along a transect facilitate measurements with different degrees of horizontal and/or vertical resolution, these computer-generated sequences (protocols) are known as arrays. Inversion algorithms are used to create a model of measured and apparent (calculated) resistivity values. Using Jacobian matrix calculations and forward modeling procedures produces values of the true resistivity, which when plotted in 2-D or 3-D are known as pseudosections. The law governing apparent resistivity $\left(p_{a}\right)$ is written as follows:

$p_{a}=k R \quad$ and

$R=V / I$

where: $k$ is the geometric factor and varies according to the quadripole array, $R$ is the resistance, $V$ is the voltage and $I$ is the current.

These plotted pseudosections are then used to examine sub-surface resistivity heterogeneities based on the differences of equipotential surfaces where they hit the ground surface at potential electrodes; the interpretation of this data is based on known resistivity ranges of geologic materials. Following on from this procedure, IP surveys measure the decay of the electrical pulse from the current electrodes as the subsurface returns to electrical equilibrium, since particular geologic materials are polarizable, some parts of the sub-surface domain essentially act as capacitors. This is particularly pertinent in the case of clays which have a high propensity for membrane polarization as a result of ion accumulations on the particles surface and hence within pore spaces (Kiberu, 2002). In essence then the IP survey is measuring the chargeability $(M)$ of sub-surface materials and this is written in the form:

$M=\frac{1}{V_{0}} \int_{t_{1}}^{t_{2}} V(t) d t$

Where $\mathrm{V}_{0}$ is voltage at time $(t) 0$, where subsequent timevoltage values are an expression of the decay of the steadystate voltage. 

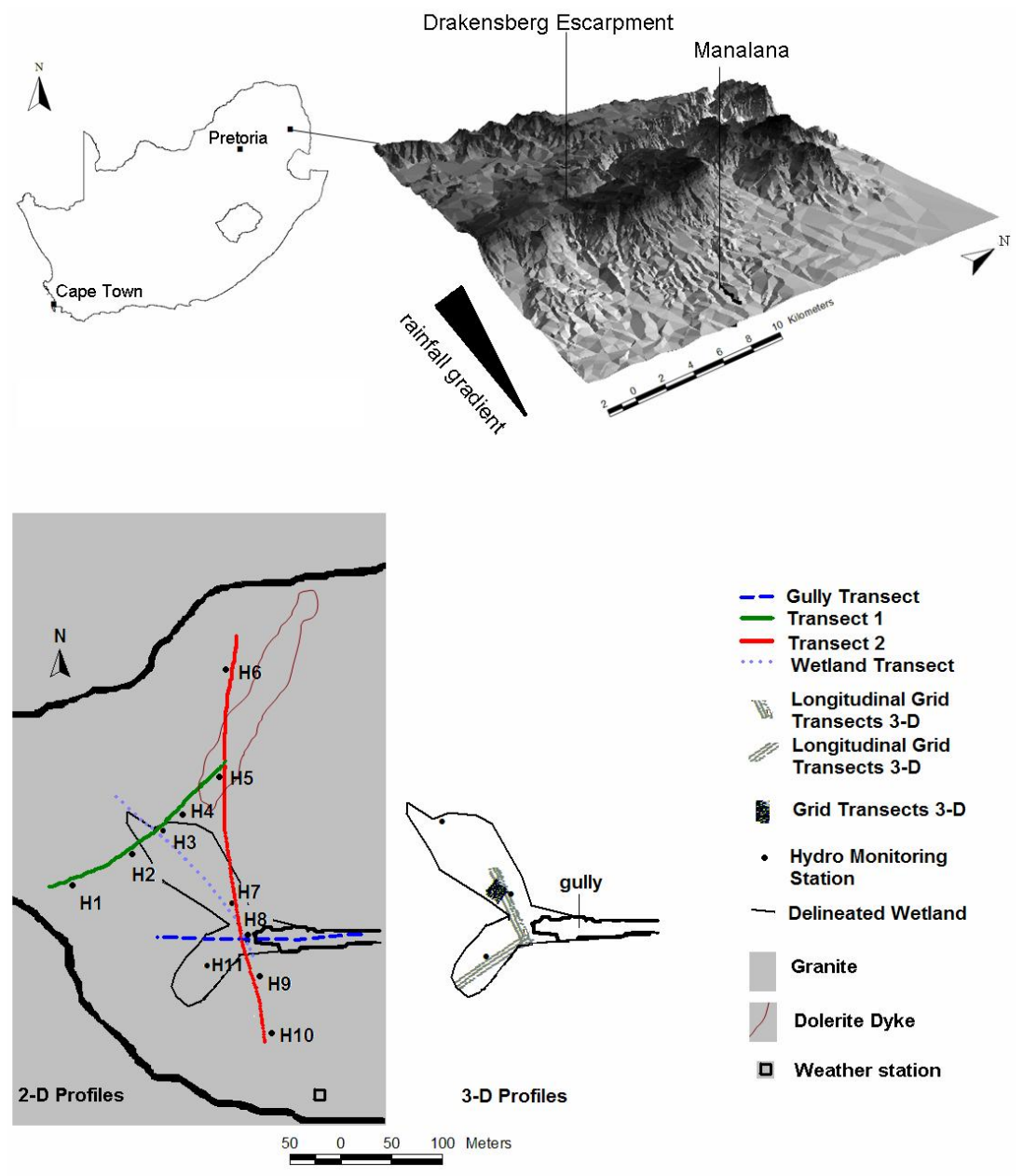

Fig. 1. Map and location of the Manalana sub-catchment within South Africa (above) with delineated wetland with the location of ERI transects and gully head (labels refer to hydrological monitoring stations).

\section{Field setting}

The study site (Fig. 1) is located within a headwater catchment of the Sand River, Mpumalanga Province, South Africa. This sub-catchment is known as the Manalana in which resides the village of Motlamogatsane (formerly known as Craigieburn). This sub-catchment as with the majority of others at the Sand River headwaters is located within the foothill zone of the northern region of the southern African escarpment. These catchments are underlain by medium to coarse grained porphyritic biotite granite frequented by extrusive dolerite dykes, and the geologies in this region are deeply weathered. The Manalana is situated within a narrow sub-humid belt along the Drakensberg escarpment with stream networks flowing west to east into the semi-arid Lowveld region, a lowland wooded savanna dominated by Acacia, Combretrum and Terminalia species. Mean annual precipitation as determined by the database of South African rainfall stations (Kunz, 2004) is $1075 \mathrm{~mm} \mathrm{a}^{-1}(1904-2000)$ with a similar evapotranspiration demand. Mean temperature at the study site between October 2006 and October 2009 was $20.9^{\circ} \mathrm{C}$. Rainfalls in this escarpment region are large and intense following the arrival of warm humid air from the south-east during the wet season which occur from October to March (Fig. 1).

Due to the dominant granitic geology, soils within the catchment are medium to coarse grained sands, and significantly, the clay concentration does not increase towards the valley bottom, hence the wetland soils are essentially sandy (Pollard et al., 2005). This description applies certainly to the near surface soils of the catchment and particularly in the valley bottom wetlands, however there are significant clay deposits at depth in the wetland and the surrounding footslopes, which are likely to be due to vertical elluviation of fine material from horizons above. Certainly the presence of certain soil forms in the catchment particularly at the footslopes suggest this to be the case, the delineated soil horizons are summarized in Table 1a and $\mathrm{b}$. 
Table 1a. Hydrometry stations in the Manalana catchment with soil form, soil moisture tension and shallow groundwater levels, and soil texture (Soil form and texture data from University of the Free State, unpublished report).

\begin{tabular}{|c|c|c|c|c|c|c|c|c|c|}
\hline & \multirow[b]{3}{*}{ Slope Element ${ }^{\mathrm{a}}$} & \multirow[b]{3}{*}{$\begin{array}{l}\text { SA Soil } \\
\text { Form }{ }^{b}\end{array}$} & \multirow[b]{3}{*}{$\mathrm{WRB}^{\mathrm{c}}$} & \multicolumn{6}{|c|}{ Sensor Depth (m) } \\
\hline & & & & 0.3 & 0.6 & 2 & 2 & 4 & 6 \\
\hline & & & & \multicolumn{3}{|c|}{$\begin{array}{l}\text { Soil Moisture Tension } \\
\text { (m) }\end{array}$} & \multicolumn{3}{|c|}{$\begin{array}{l}\text { Shallow Groundwater level } \\
\text { (m) }\end{array}$} \\
\hline & October 2006 & & & & & & & & \\
\hline H5 & Backslope & Oakleaf & Regosol & 3.39 & 4.11 & 3.22 & & & None. obs. \\
\hline H6 & Shoulder & Glenrosa & Leptosol & 15.20 & 87.80 & 10.31 & & None. obs. & \\
\hline H7 & $\begin{array}{l}\text { Toeslope } \\
\text { (wetland) }\end{array}$ & Katspruit & Gleysol & & 4.61 & 0.41 & -2.81 & -4.40 & \\
\hline H8 & $\begin{array}{l}\text { Toeslope } \\
\text { (wetland) }\end{array}$ & Kroonstad & Planosol & & & 3.05 & -4.52 & & \\
\hline H9 & Foot-slope & Oakleaf & Regosol & & & 3.92 & None. obs. & & None. obs. \\
\hline \multirow[t]{2}{*}{$\mathrm{H} 10$} & Backslope & Oakleaf & Regosol & 8.72 & 25.54 & 18.26 & & & \\
\hline & November 2006 & & & & & & & & \\
\hline $\mathrm{H} 1$ & Backslope & Glenrosa & Leptosol & 3.00 & 5.50 & 4.53 & & None. obs. & \\
\hline $\mathrm{H} 2$ & Foot-slope & Kroonstad & Planosol & 0.41 & 0.63 & -0.24 & None. obs. & & None. obs. \\
\hline $\mathrm{H} 3$ & $\begin{array}{l}\text { Toeslope } \\
\text { (wetland) }\end{array}$ & Katspruit & Gleysol & & 1.21 & 0.31 & -2.20 & & \\
\hline $\mathrm{H} 4$ & Foot-slope & Kroonstad & Planosol & 2.22 & & 2.02 & -5.32 & & \\
\hline H5 & Backslope & Oakleaf & Regosol & 1.38 & 1.17 & 4.49 & & & None. obs. \\
\hline H6 & Shoulder & Glenrosa & Leptosol & 1.60 & 4.14 & 9.45 & & None. obs. & \\
\hline
\end{tabular}

${ }^{a}$ Slope Element based on classification by Ruhe (1960).

${ }^{b}$ South African Soil Form classification by Soil Classification Working Group (1991).

c World Reference Base soil classification, FAO (1998).

\section{Table 1b.}

\begin{tabular}{|c|c|c|c|c|c|c|c|}
\hline & Horizon & Depth (m) & Texture $^{\mathrm{a}}$ & & Horizon & Depth (m) & Texture $^{\mathrm{a}}$ \\
\hline \multirow[t]{2}{*}{$\mathrm{H} 1$} & A & $0-0.2$ & sandy loam - sandy clay loam & H6 & A & $0-0.4$ & sandy loam \\
\hline & B & $0.2-1.2$ & sandy clay loam & & B & $0.4-1.4$ & sandy clay loam \\
\hline \multirow[t]{2}{*}{$\mathrm{H} 2$} & A & $0-0.4$ & sandy clay loam & $\mathrm{H} 7$ & A & $0-0-.4$ & sandy loam - sandy clay loam \\
\hline & G & $0.4-1.0$ & clay & & $\mathrm{E}$ & $0.4-0.9$ & sandy clay loam \\
\hline \multirow[t]{6}{*}{$\mathrm{H} 3$} & A & $0-0.3$ & sandy loam - sandy clay loam & & G & $0.9-1.7$ & clay loam \\
\hline & G & $0.3-0.4$ & clay loam & $\mathrm{H} 8$ & A & $0-0.2$ & sandy loam - sandy clay loam \\
\hline & G & $0.4-0.7$ & clay - clay loam & & B & $0.2-0.8$ & sandy loam - sandy clay loam \\
\hline & G & $0.7-1.3$ & clay - clay loam & & B & $0.8-1.0$ & sandy clay loam \\
\hline & G & $1.3-1.5$ & clay & & B & $1.0-1.9$ & sandy clay loam \\
\hline & G & $1.5-2.0$ & clay - clay loam & H9 & A & $0-0.1$ & sandy loam - sandy clay loam \\
\hline \multirow[t]{4}{*}{$\mathrm{H} 4$} & A & $0-0.3$ & sandy loam & & B & $0.1-0.6$ & sandy clay loam \\
\hline & $\mathrm{E}$ & $0.3-0.6$ & clay loam & & B & $0.6-1.0$ & sandy clay \\
\hline & $\mathrm{E}$ & $0.6-1.1$ & clay - clay loam & & B & $1.0-1.7$ & clay loam \\
\hline & G & $1.1-1.7$ & clay & H10 & A & $0-0.3$ & sandy clay loam \\
\hline \multirow[t]{4}{*}{ H5 } & A & $0-0.2$ & sandy loam & & B & $0.3-1.1$ & sandy clay loam \\
\hline & B & $0.2-0.6$ & sandy clay loam & & $\mathrm{C}$ & $1.1-1.7$ & clay loam \\
\hline & B & $0.6-1.4$ & sandy clay loam & & & & \\
\hline & B & $1.4-2.0$ & clay - clay loam & & & & \\
\hline
\end{tabular}

${ }^{\text {a }}$ United States Department of Agriculture. 
According to the South African vegetation type classification system (Acocks, 1988) this area falls under the lowveld sour bushveld. Land use within the Manalana is essentially densely populated rural housing of the communal land tenure typical of the area including a dense network of roads and pathways. A combination of dry-upland and wetland-valley bottom small holder subsistence cultivation characterizes the area. The Manalana catchment is highly altered in its vegetation composition than would normally be found in more pristine areas of the lowveld sour bushveld. The hillslopes were in part cleared for forestry in the 1960-70 s and never planted, as such the short opportunistic shrub, Parinari curatellifolia now dominates. The presence of this shrub, as well as communal grazing of cattle, frequent grassland fires, and harvesting of grass and fuel wood has rendered a catchment with a very low basal cover. In addition, it is extensive wetland cultivation (ridge and furrow systems) that has altered the natural micro-topography of the valley bottom and changed the balance of hydro-geomorphic processes within the wetland system. This may take the form of disaggregating material through tillage practices, as well as increasing the level of channelization within the system by furrowing, amongst several other factors for example. This is believed to be a causative agent facilitating the extensive gullying characterizing the Manalana catchment. The Manalana catchment itself is $2.61 \mathrm{~km}^{2}$ of which $2.50 \mathrm{~km}^{2}$ and $0.11 \mathrm{~km}^{2}$ (or $95.6 \%$ and $4.4 \%$ ) make up the area of interfluve and wetland respectively. Whilst the wetlands had traditionally been used for subsistence agriculture, the wetland in the study area of the catchment has remained fallow and had since returned to a vegetation community of emergent wetland vegetation dominated by Phragmites mauritianus.

\section{Methods and techniques}

\subsection{Overall approach}

Since the commencement of the catchment hydrological monitoring program (September 2005) various 2-D ERI surveys were undertaken along transects through the wetland and its contributing catchment. These were followed in JulyAugust 2008 with a detailed 3-D ERI and IP approach to ascertain the distribution of the sub-surface clay-plugs and allow for some speculation on their development. In both cases use was made of an $\mathrm{ABEM}^{\mathrm{TM}}$ SAS1000 single channel Lund imaging system (Terrameter and switcher unit) with 64 electrode take-out over four cables. Electrode spacing and array types varied with each survey according to information requirements, a summary of these are given in Table 2. In general the Wenner array was used as this is sensitive to vertical changes in the subsurface resistivity distribution and anticipated to be useful for delineating sedimentary layers. Meanwhile, the Schlumberger array was used specifically on transect 1 as this array is sensitive to both vertical and horizontal resistivity distributions and therefore anticipated to be useful for revealing intruding features such as bedrock outcrops, this array was used principally to assist in a complementary study in the catchment on hillslope hydrology. Orientation of these surveys is displayed in Fig. 1. Inversion of 2-D and 3-D datasets were conducted using the RES2DINV and RES3DINV software packages respectively (Loke, 2005a, 2005b). Prior to the final inversion of data, the raw electrical resistivity data was assessed for its quality according to the methods of Loke (2004), where bad data points are removed from a preliminary inversion array that display high RMS error. These bad data points are therefore excluded from the final data inversion process. Inversion data were georeferenced with correct elevations using a Trimble ${ }^{\circledR}$ Pro-XRS differential Global Position System.

\subsection{3-D approach}

The first part of the 3-D study sought to examine the location and extent of the clay-plugs within the wetland. For this purpose three parallel transects were placed at longitudinal orientation in the two arms of the wetland (as shown in Fig. 1), forming a juncture adjacent to the erosion gully head. Wenner- $\alpha$ arrays were used in each of the parallel transects using a single time interval IP sequence which also records the sub-surface resistivity distribution at the same time, a default setting in the ABEM system.

The second part of the 3-D approach sought to examine the interface between the hillslope and valley bottom (wetland) in order to determine whether these clay-plug zones are contiguous with the hillslope, i.e. at the interface of the wetland with the footslope. Here one location was chosen (Fig. 1) for detailed examination, in which it was hoped that any layered lithographic effects within the wetland substrate could also be discerned. Due to the small localized setting of this particular investigation and due to considerations in terms of the data acquisition time, new protocols were written such that Wenner- $\beta$ arrays could be deployed using a single cable with a 21 electrode take-out (NB: the system consists of 4 cables, each of 21 take-out positions). This allowed for 3 subsequent transects to be set-up whilst the ABEM system was logging another. Referring to Fig. 2, the survey took the form of a gridded system made up of two orientations of 11 parallel transects, in both $X$ and $Y$ directions, making up a total of 22 parallel lines. Electrodes were spaced at $0.75 \mathrm{~m}$ intervals, and thus the total length of each individual transect was $15 \mathrm{~m}$. Correct geometric factors $(k)$ were applied to the raw data in order to recalculate the apparent resistivity, prior to the inversion of the data set since the ABEM system limits the electrode spacing to metre integer values with one decimal place. Hence, the apparent resistivity distributions would be different to those that would otherwise have been calculated automatically by the ABEM system.

In both 3-D approaches the resulting images are quasi-3$\mathrm{D}$ as results are interpolated from 2-D transects, and the one 
Table 2. 2-D ERI surveys timing and arrays deployed in the Manalana catchment.

\begin{tabular}{|c|c|c|c|c|c|}
\hline ERT Survey & array type & $\begin{array}{l}\text { electrode } \\
\text { spacing }(\mathrm{m})\end{array}$ & date of survey & orientation & purpose \\
\hline $\begin{array}{l}\text { Gully longitudinal } \\
\text { transect }\end{array}$ & Wenner- $\alpha$ (long) & 2.5 & May 2005 & W-E & $\begin{array}{l}\text { material and bedrock } \\
\text { distribution } \\
\text { wetland and gully floor }\end{array}$ \\
\hline Transect 1 & $\begin{array}{l}\text { Schlumberger } \\
\text { (short) }\end{array}$ & $5^{\mathrm{a}}$ & November 2006 & SW-NE & $\begin{array}{l}\text { material and bedrock } \\
\text { distribution } \\
\text { hillslope-wetland-hillslope }\end{array}$ \\
\hline Transect 2 & Wenner- $\alpha$ (long) & 5 & October 2006 & $\mathrm{~S}-\mathrm{N}$ & $\begin{array}{l}\text { material and bedrock } \\
\text { distribution } \\
\text { hillslope-wetland-hillslope }\end{array}$ \\
\hline Wetland transect & Wenner- $\alpha$ (short) & $5^{\mathrm{a}}$ & October 2006 & NW-SE & $\begin{array}{l}\text { material and bedrock } \\
\text { distribution }\end{array}$ \\
\hline $\begin{array}{l}\text { Longitudinal Grid } \\
\text { Transects 3-D }\end{array}$ & Wenner- $\alpha$ (long) & 2 & July 2008 & $\begin{array}{l}\text { SW-NE \& } \\
\text { SE-NW }\end{array}$ & $\begin{array}{l}\text { identify clay distribution } \\
\text { underlying wetland }\end{array}$ \\
\hline Grid Transects 3-D & $\begin{array}{l}\text { Wenner- } \beta \\
\text { ( } 21 \text { probe) }\end{array}$ & 0.75 & August 2008 & SW-SE-NE-NW & $\begin{array}{l}\text { identify clay distribution at } \\
\text { wetland-footslope interface }\end{array}$ \\
\hline
\end{tabular}

a used model refinement in inversion to half unit electrode spacing, this allows for dampening of the effect of high resistivity variations that may be encountered in a survey and provides for smoother inversion of resistivity data.

channel SAS1000 ABEM system is limited in this regard. Also parallel transects were placed apart at two times the unit electrode spacing, within the bounds of acceptable error for a quasi-3-D approach (Loke, 1999). A brief explanation of this is warranted: up to this point discussion has focused on the vertical sensitivity of the electrodes to produce a 2-D pseudosection, meanwhile electrodes also exert a radial sensitivity around themselves which becomes important where data is acquired and interpolated through inversion techniques in 3-D. The reader is referred to Loke (1999) for a more detailed explanation. In both 3-D approaches used here, data of 3-D transect "blocks" were defined by the "collate 2-D to 3-D function" within RES2DINV and inverted in RES3DINV. This function takes a series of 2-D surveys (2-D data files) and through an interpolation technique based on known co-ordinates of each electrode produces a 3-D data file. Again, data with high RMS error were removed from the 2-D data arrays prior to final inversion in RES3DINV. 3D images were plotted using Rockworks ${ }^{\circledR} 2006$ software for visualizing earth surface and sub-surface data.

The presence of groundwater has an effect on the resistivity range of earth materials (Loke, 2004) and in order to achieve maximum clarity in terms of interpreting these 3$\mathrm{D}$ data, the dry winter period is most appropriate for data collection. Therefore, these surveys were conducted during July-August 2008, during the mid winter period and height of the dry season for this region. Consequently this wetland had undergone a period of desiccation following the cessation of the rains earlier in the year, and as a result, the influence of groundwater on the resistivity and IP soundings was at the minimum possibly achievable for this wetland system. A qualitative ground-truthing was also undertaken of the 3-D transects, using a series of random auger samples where the depth to a change in soil texture was noted, specifically where a change in material dominated by sand fraction switched to that dominated by clay, using a bolus test (Tongway and Hindley, 2004).

\subsection{Supporting hydrometry}

As part of the hydrological monitoring study undertaken within the Manalana catchment two forms of data are used to assist in the verification and interpretation of ERI and IP data. These are simply shallow groundwater piezometer data, which were measured using regular (bi-/tri-weekly) dip meter readings in nested groundwater piezometers at hydrological monitoring stations within the wetland. The locations of these stations are located in Fig. 1. Moreover, these piezometers were also the subject of in-situ saturated hydraulic conductivity analysis, which took the form of bail tests using the method of Bouwer and Rice (1976), which takes the form:

$K=\frac{r_{c}^{2} \ln \left(R_{e} / r_{w}\right)}{2 L} \frac{1}{t} \ln \frac{y_{0}}{y_{t}}$

where: $K$ is the hydraulic conductivity of the wetland material, $L$ is the height of the open screen portion of the piezometer at its interface with the wetland matrix $(300 \mathrm{~mm}), y$ is the vertical distance between water level in the piezometer and that within the wetland material at equilibrium at time 0 and time $t . R_{e}$ is the effective radius over which $y$ is dissipated 


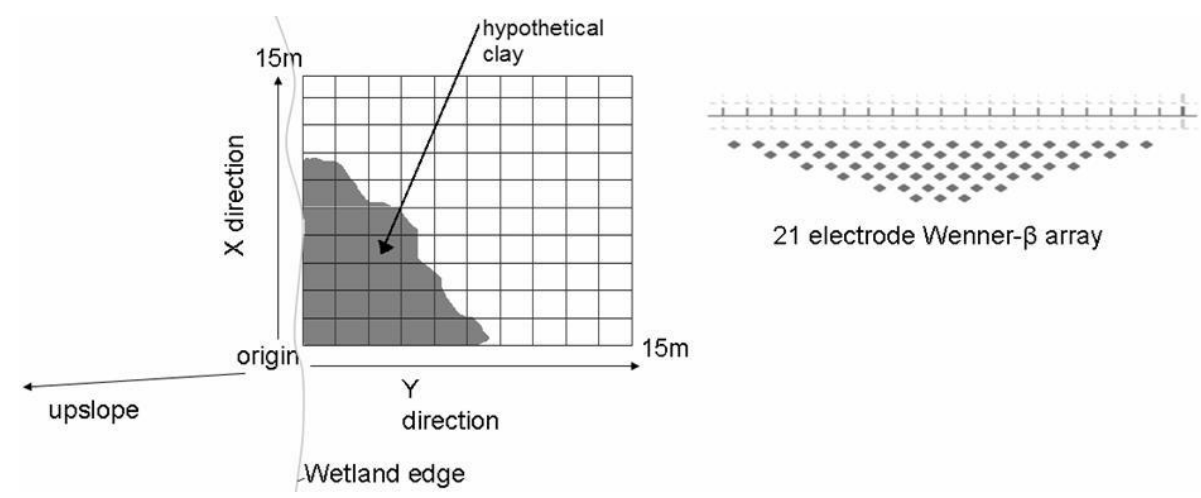

Fig. 2. Grid design and placement of the Wenner- $\beta \times 21$ transects at the wetland-footslope interface and the data point distribution of the 2-D array (whose series along the grid would be used to interpolate a 3-D profile).

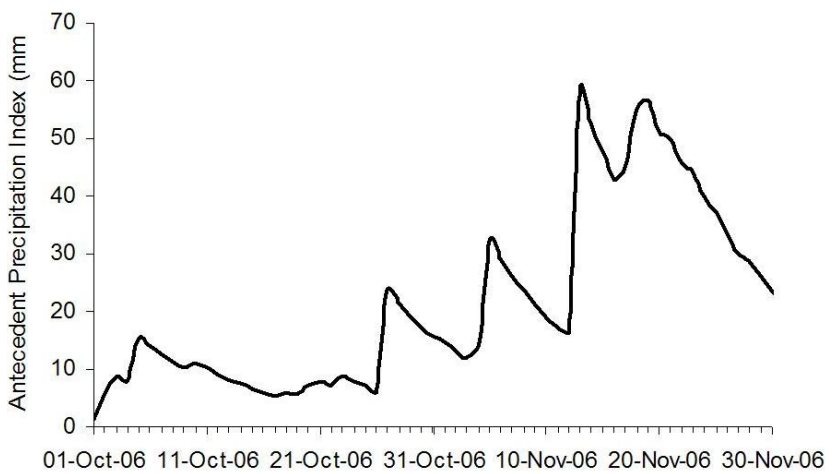

Fig. 3. Antecedent Precipitation Index for the period OctoberNovember 2006.

and $r_{w}$ is the horizontal radius between the centre of the piezometer and the aquifer (plus well casing and interfacing material, $42 \mathrm{~mm}) . \quad r_{c}$ is the inside radius of the piezometer casing $(27 \mathrm{~mm})$.

In addition, mean soil moisture tension (tensiometers) and shallow groundwater levels for the months of October and November 2006 are displayed in Table 1 to assist in the interpretation of ERI data. Moreover an antecedent precipitation index (API) for these two months is also displayed in Fig. 3, this is based on the method described by Kohler and Linlsey (1951), and commences at the start of the hydrological year in eastern South Africa (October).

\section{Results}

\subsection{2-D surveys}

Figure 4 displays the subsurface resistivity distribution where the un-eroded wetland surface descends into the erosion gully at horizontal distance $-35 \mathrm{~m}$ on the lateral transect. The area between $-55 \mathrm{~m}$ and $-35 \mathrm{~m}$ is characterized by emergent wetland vegetation namely $P$. mauritianus and con- tains a network of drainage furrows, note one such furrow at $-50 \mathrm{~m}$. The first point of interest is the shallow resistant overburden (400-1400 $\Omega \mathrm{m}$ ) overlying a conductive horizon (30-150 $\Omega \mathrm{m}$ ) between $-45 \mathrm{~m}$ and $-20 \mathrm{~m}$, underlain by a deeper resistant layer $(>250 \Omega \mathrm{m})$. The second is the vertical protrusions that appear at $-15 \mathrm{~m}$ and $30 \mathrm{~m}$ on the lateral transect. Interpretation of these points reveals the nature of unconsolidated and transported sediments (sands) at the wetland surface and gully floor which overly deep leached fine clay deposits, which are confined by these vertical felsic saprolitic protrusions from the underlying granitic bedrock. Since it is known that the dominant geology of the catchment is granitic, the associated resistivity ranges for this bedrock type are used for ERI interpretation based on geological resistivity ranges provided by Sharma (2008). These vertical protrusions could therefore be interpreted as sub-surface controls intersecting the unconsolidated wetland sediments. This in essence shows that the wetland is characterized by what appears to be a series of semi-confined aquifers with high water retention capacity due to their clay content. This is highlighted by the sharp transitions between the two material types at depths below $2 \mathrm{~m}$ (i.e. low resistivity clays versus high resistivity bedrock/saprolite). The significance of this observation is particularly important for the way that the wetland retains water and further hydrochemical analysis will reveal the nature of the groundwater recharge processes that these wetlands facilitate, within the confines of these bedrock controls.

Catchment ERI cross-sections were made perpendicular to the orientation of the wetland along two instrumented transects, transects 1 and 2 (Figs. 5 and 6). In Fig. 5 the region $-100 \mathrm{~m}$ to $-20 \mathrm{~m}$ is dominated by the opportunist shrub P. curatellifolia, and between $-20 \mathrm{~m}$ and $20 \mathrm{~m}$ by P. mauritianus dominated wetland vegetation, and thereafter the hillslopes are again characterised by $P$. curatellifolia shrubland. The same vegetation sequence is observed in Fig. 6 between $-200 \mathrm{~m}$ to $-110 \mathrm{~m},-110 \mathrm{~m}$ to $30 \mathrm{~m}$, and 30 to $200 \mathrm{~m}$ respectively. The valley bottom area in Fig. 5 is an area of wetland that has not been used extensively for subsistence agriculture, 


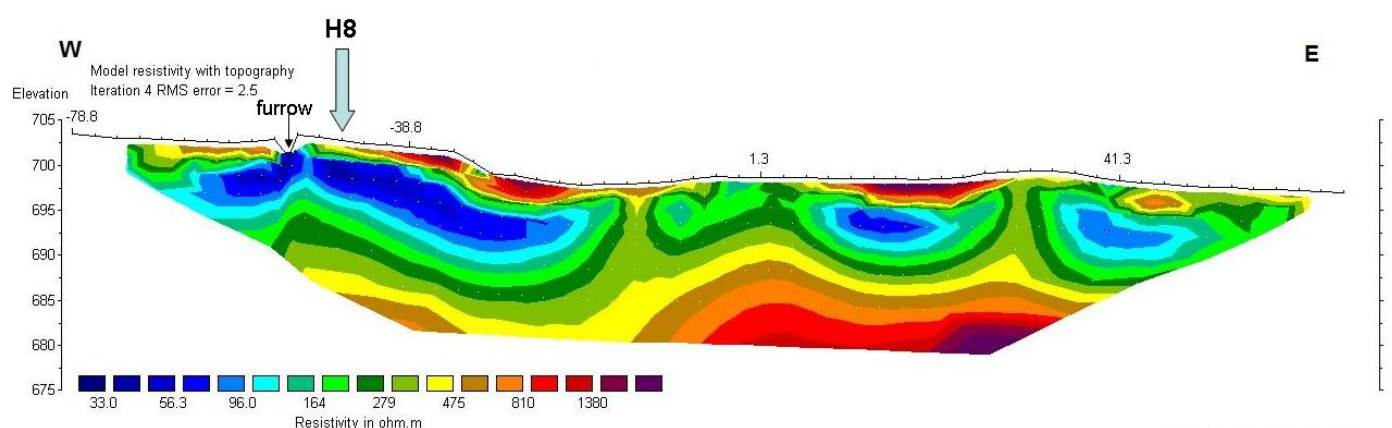

Horizontal scale is 20.67 pixels per unit spacing

Vertical exaggeration in model section display $=1.00$

Last electrode is located at $66.3 \mathrm{~m}$

Fig. 4. Longitudinal ERI pseudosection of a transect along erosion gully. (Wenner long). NB. This survey was conducted prior to the installation of hydrometric apparatus.

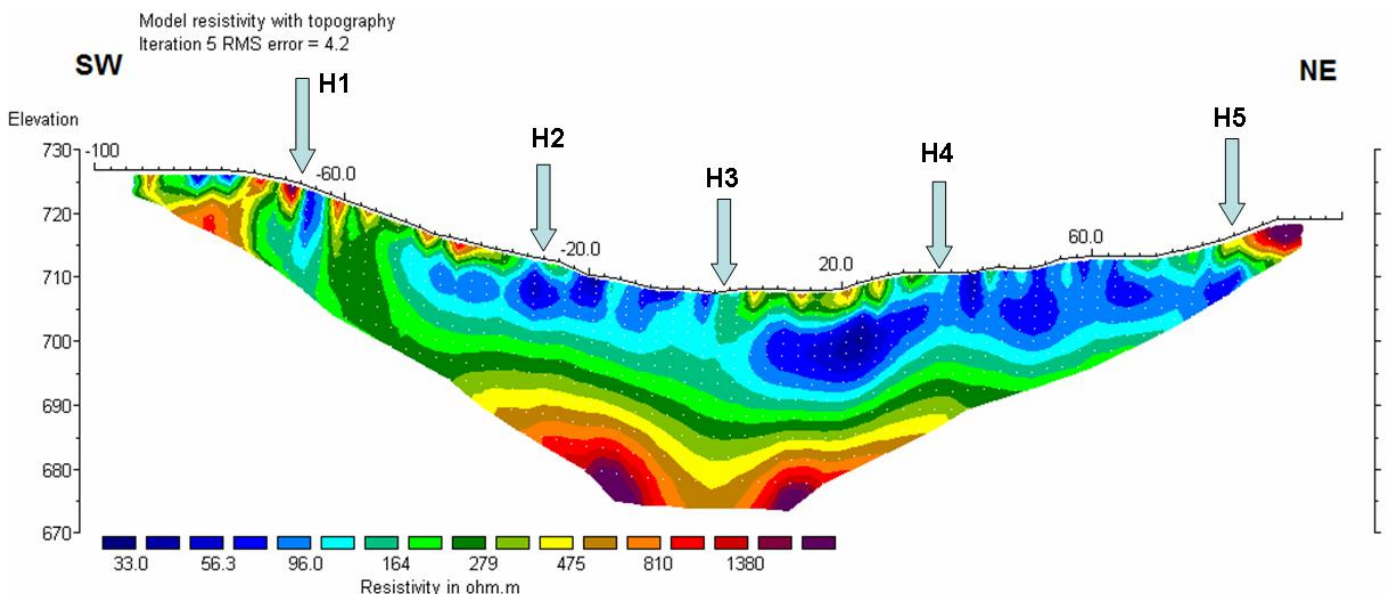

Horizontal scale is 11.68 pixels per unit spacing

Vertical exaggeration in model section display $=1.00$

First electrode is located at $-100.0 \mathrm{~m}$

Last electrode is located at $100.0 \mathrm{~m}$.

Fig. 5. ERI pseudosection of Transect 1 (hillslope-wetland-hillslope) (Schlumberger short).

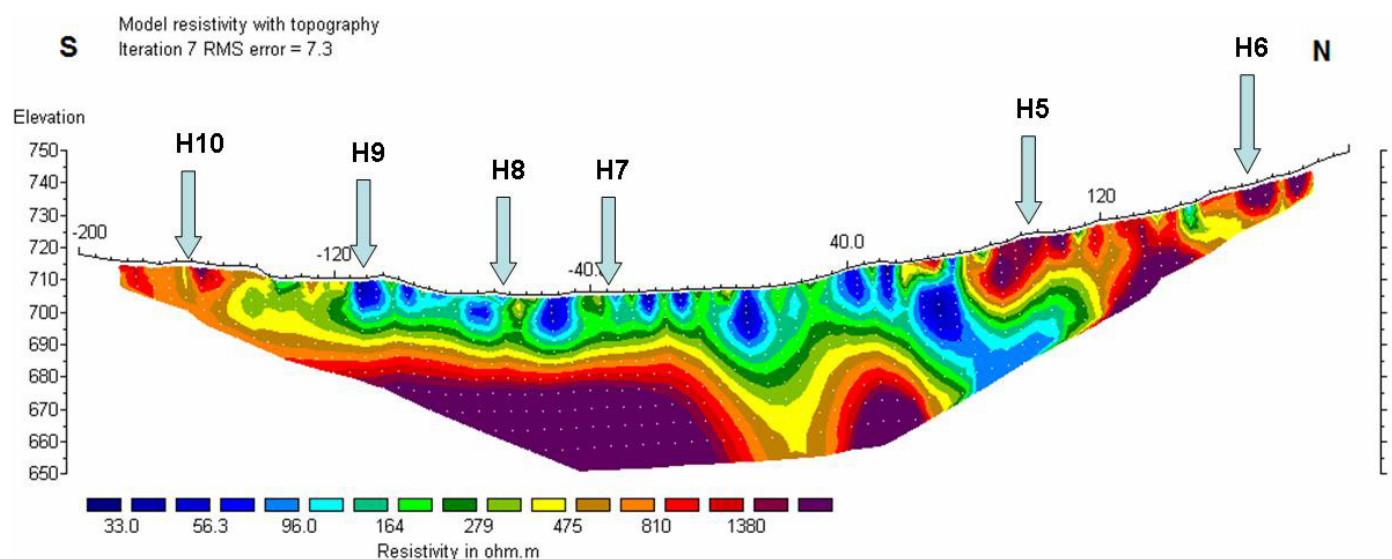

Horizontal scale is 11.68 pixels per unit spacing

Unit Electrode Spacing $=5.00 \mathrm{~m}$

Vertical exaggeration in model section display $=1.00$

First electrode is located at $-200.0 \mathrm{~m}$

Last electrode is located at $200.0 \mathrm{~m}$.

Fig. 6. ERI pseudosection of Transect 2 (Wenner long). 


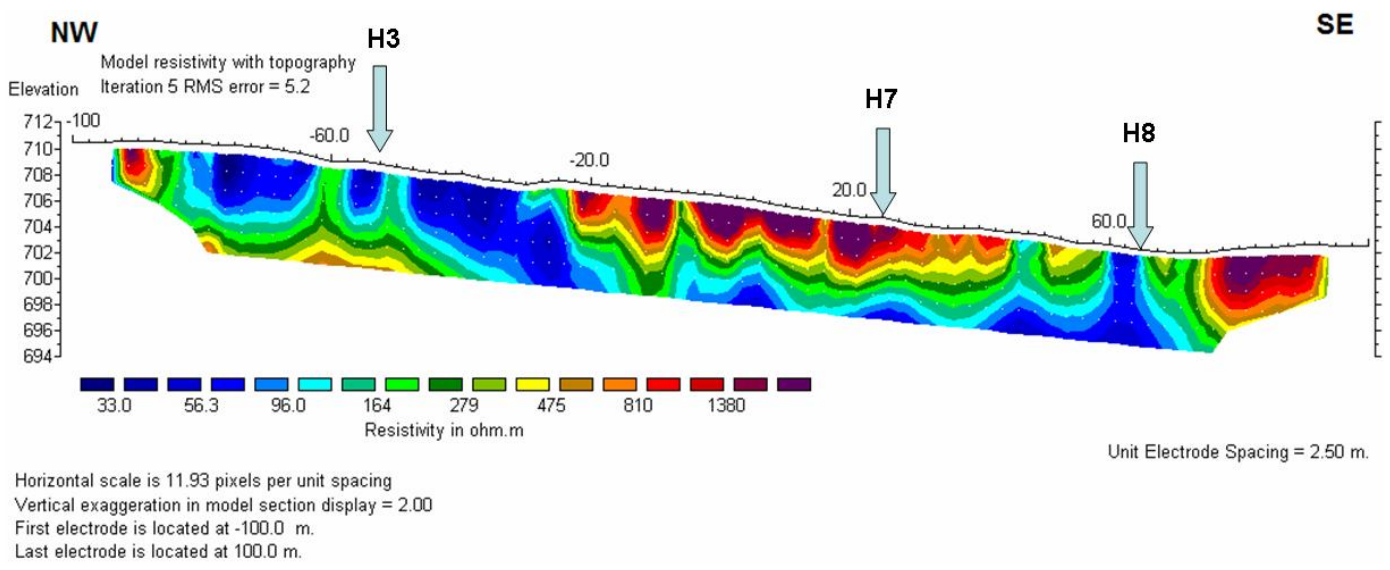

Fig. 7. ERI pseudosection of a transect along the wetland. Wenner short, note $2 \times$ vertical scale exaggeration.

meanwhile the valley bottom area of Fig. 6 has been, and it contains a large network of ridge and furrow systems. In both cases the substrate appears to be increasingly conductive towards the valley bottom and underlain by higher resistant material. The unconsolidated wetland substrates of the valley bottom appear to be some $20-25 \mathrm{~m}$ deep and are probably of a more conductive nature due to the higher moisture content of the substrates in this region than on the interfluves. In Fig. 5 it is apparent that the interfluve of the NE side of the transect is more conductive than the SW side. This is due to the intersection of the catchment's northern edge by a doleritic dyke, noted through in-situ observations, whereas the SW is a slope of granitic material. This is seen again in Fig. 6 for the $\mathrm{S}-\mathrm{N}$ transect, the doleritic dyke is more apparent between $50-100 \mathrm{~m}$ with a vertical structure of $<150 \Omega \mathrm{m}$ extending to the base of the pseudosection. Further to the north of this transect in the upslope region the granitic geology reappears.

These initial 2-D ERI surveys reveal the interplay of bedrock and regolith that characterizes this particular catchment. In particular there is an obvious contrast between the two geological substrates by way of the predominant granitic material and flanking of the catchments by dolerite dykes. This interplay of geologies has important ramifications for the hydrological processes operating within this catchment, particularly since soil hydraulics will be influenced by the different soil textures and porosities yielded from soils on these different geologies. Most notably granites weather to coarse structured soils and dolerites to fine clay rich soils (Schaetzl and Anderson, 2005), and this was reflected by the contrasting conductivities of the materials in Figs. 5 and 6. Hence the lower resistance of the doleritic material is explained by its higher clay content than the opposing granites. The observed hydrological responses reflecting these differing hillslope geologies to precipitation events and antecedent soil moisture conditions, and the consequent variability in the way that water is delivered to the valley bottom wetland have been characterized for this catchment. This has been done through hydrometric observations and hydropedological interpretation of soil form (Riddell et al., 2010).

The entire profile of Fig. 7. has emergent wetland vegetation at the surface, dominated by P. mauritianus and subsistence agriculture occurred primarily between $-30 \mathrm{~m}$ and $70 \mathrm{~m}$. As expected, increasingly conductive material is observed within the longitudinal pseudosection displayed in Fig. 7, in particular the $<100 \Omega \mathrm{m}$ material on the northern side of the transect which corresponds with the valley bottom material of Fig. 5. This conductive material is seen all along the profile although it is shallower with reduced depth to bedrock at the northern end. However, between $-20 \mathrm{~m}$ and $40 \mathrm{~m}$ a more resistant ( $>1000 \Omega \mathrm{m}$ ) layer is seen at the surface. This resistant layer is an area where the wetland topography has been mechanically altered by subsistence agricultural practices. The creation of ridge and furrow systems by digging and re-deposition of material in this way has consequently disaggregated the wetland substrate, reducing its bulk density and hence inducing higher relative apparent resistivity. The furrows themselves are up to approximately $1 \mathrm{~m}$ deep, below the top of the raised cultivation beds. It is likely that the traversing of the resistivity probes and cables across both the furrows and raised cultivation beds has allowed for a certain degree of distortion of the observed vertical resistivity distribution in this region of the wetland, allowing for an over exaggerated measurement of resistant material at depth. A significant observation from this pseudosection is the apparent vertical protrusions of high conductivity material at $60 \mathrm{~m}$ and a similar possible structure at $45 \mathrm{~m}$ (contrasting with the high resistant protrusions of Fig. 5). At the extreme SE of this image a large area of high resistant material occurs and this forms the eroded and deposited sediments of the erosion gully head, corresponding to $-40 \mathrm{~m}$ in Fig. 4 . 
The fact that the longitudinal wetland survey (Fig. 7) revealed vertical low resistance structures toward the wetland toe added support to the speculation that sub-surface flows of water through this highly conductive sandy system were buffered by clay-plugs. Furthermore, these were deemed to explain the lateral differences in hydrodynamics of the phreatic surface responses at different longitudinal reaches within the system (Riddell et al., 2007). This was noted because the hydrodynamics of the wetland appeared to be partly de-coupled between longitudinal reaches of these wetlands where these clay-plugs had formed sub-surface hydrodynamic breaks in an otherwise sandy and hydraulically conductive system. Similar responses to this were also noted during the 2007-2008 hydrological season where this hydrodynamic break was observed between groundwater levels as recorded at the hydrometry stations. Figure 8 reveals the hydrodynamic responses in paired peizometers $(2 \mathrm{~m}$ and $4 \mathrm{~m}$ deep) to rainfall over this season. It is quite clear that the ground water table has a short lived elevation at the most head-ward reach of the wetland at $\mathrm{H} 3$, particularly during the peak of rainfall up to March 2008 as seen in both piezometers. Thereafter, following the cessation of the rains the water table drops below the depth of the $2 \mathrm{~m}$ piezometer and there follows a steady decline in water table elevation observed in the $4 \mathrm{~m}$ piezometer. Since both piezometers at H3 show similar water table levels this suggests that they both intersect the same aquiferous material in the wetland. Meanwhile moving downstream to $\mathrm{H} 7$ the perpetuity of the groundwater level is more sustained. However, whilst water table behaviour between the two piezometers at $\mathrm{H} 7$ tallies, there is a discrepancy in their depths of between $0.5-1.0 \mathrm{~m}$ over time, suggesting a degree of discontinuity in the aquifer material at depth somewhere between $2-4 \mathrm{~m}$ deep. This perpetuity however is to be expected since the contributing area of the catchment and the wetland to this point is considerably greater than at H3. However as one moves downstream this expected perpetuity of groundwater level elevation at $\mathrm{H} 8$ is rescinded earlier than at the upstream $\mathrm{H} 7$, and in fact the water table in the $2 \mathrm{~m}$ piezometer here declines prior to that at $\mathrm{H} 7$, furthermore the $4 \mathrm{~m}$ piezometer here shows a very dampened response to rainfall and never exceeds $-2.5 \mathrm{~m}$. This is attributed to the location of $\mathrm{H} 8$ adjacent to the erosion gully head, which facilitates a drawdown of water from the wetland at this location, and this may be noted by the fact that the water levels in both piezometers at $\mathrm{H} 8$ are considerably lower than at $\mathrm{H} 7$. It would however also be expected that this erosion gully would facilitate a hydraulic drawdown that would also be felt at the nearby H7. Despite this the water table elevations at $\mathrm{H} 7 \mathrm{re-}$ main quite close to the surface long after the piezometers at H8 have begun to dry out. This supports the notion that the presence of the clay-plug as seen in Fig. 7, buffers the lateral sub-surface flow of water between $\mathrm{H} 7$ and $\mathrm{H} 8$.

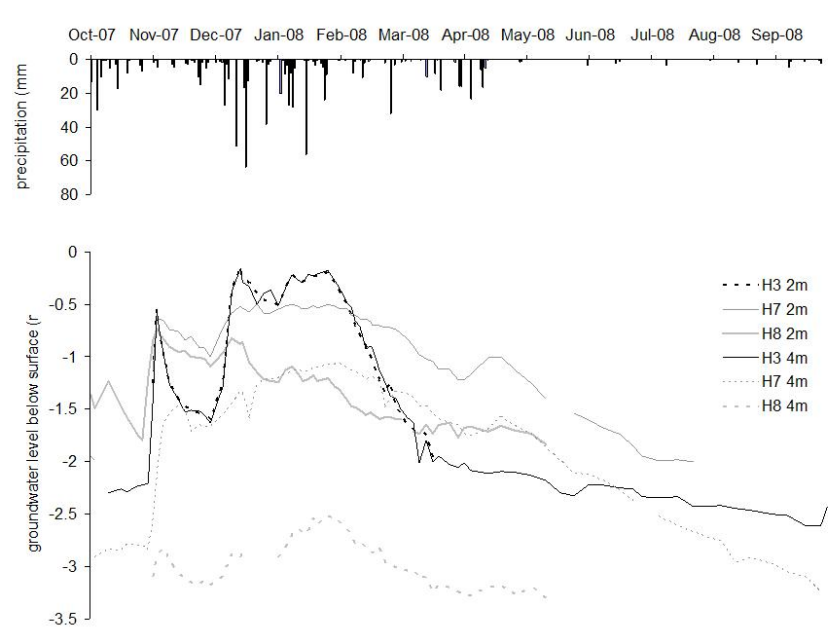

Fig. 8. Hydrometric observations of water table depths within the Manalana wetland October 2007-October 2008 (2 m and $4 \mathrm{~m}$ refer to installed piezometer depths).

\subsection{3-D surveys}

3-D geophysical surveys where used to analyze the distribution of clay bodies within the Manalana wetland and IP surveys were of particular use. 3-D pseudosections are displayed in Fig. 9 for the series of parallel transects orientated SE-NW longitudinally through the wetland. Here one observes the relatively low chargeability of the material within the vicinity of the origin of the pseudosection. However within this material three other factors are apparent. First, the chargeability time increases with distance away from the origin, particularly at a distance beyond $\sim 55 \mathrm{~m}$, and this increases significantly towards the surface of the profile beyond this point. The second observation to consider is the sinuous curve made by the material with a chargeability of between $1-2 \mathrm{~ms}$ at around $55 \mathrm{~m}$. The final and rather striking observation is the arch-like appearance of extremely high capacitance $(\sim 0.01-0.03 \mathrm{~ms})$ material from the origin to $\sim 50 \mathrm{~m}$. The vertical sections of this arch-like structure correspond to the vertical low resistivity material mentioned in the discussion of Fig. 7. Furthermore, the chargeability distribution does not appear to change within the $4 \mathrm{~m}$ breadth of the profile, except for a slightly lower chargeability region $(\sim 0.03 \mathrm{~ms})$ at around $20 \mathrm{~m}$ at $4 \mathrm{~m}$ breadth. Figure 10 displays the same transect except in terms of the subsurface resistivity distribution, and here similarities emerge as would be expected. These being for instance the profile in Fig. 10 which is dominated by conductive material generally no more than $1000 \Omega \mathrm{m}$, which conforms to the high capacitance material of Fig. 9. Meanwhile a band of high resistance material $(>1000 \Omega \mathrm{m})$ is encountered in Fig. 10 in the subsurface below where the high capacitance arch is discernable in Fig. 8, approximately between $5-35 \mathrm{~m}$ in Fig. 10. Furthermore, higher resistance material $(>1000 \Omega \mathrm{m})$ is observed 


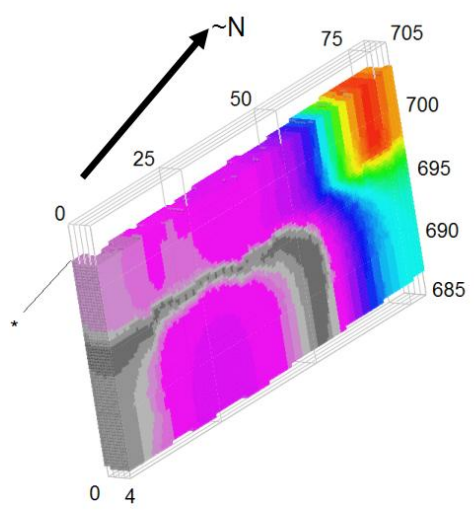

*origin: $30.97532,-24.66752$

Fig. 9. Pseudo 3-D IP section of the SE-NW parallel transects. Scales are in metres diverging from a geographical origin, vertical scale is altitude a.s.1. (Wenner long, $2 \mathrm{~m}$ spacing, 8th iteration, RMS error $8.74 \%$ ).
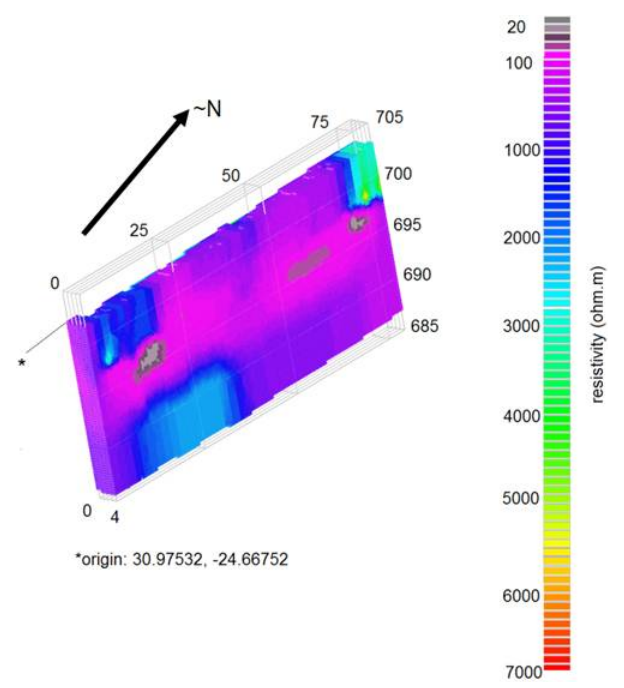

Fig. 10. Pseudo 3-D resistivity section of the SE-NW parallel transects. Scales are in metres diverging from a geographical origin, vertical scale is altitude a.s.1. (Wenner long, $2 \mathrm{~m}$ spacing, 8th iteration, RMS error $6.36 \%$ ).

beyond $70 \mathrm{~m}$ near the surface in Fig. 10 when compared to the rest of the pseudosection, corresponding to the lower capacitance material in Fig. 9. However the major difference between the two images relates to the clearer definition of an arch-type distribution of material in Fig. 9, this is not revealed in Fig. 10.

The IP profile of the SW-NE orientated transect (Fig. 11) has a high capacitance material throughout the profile, seldom exceeding $0.1 \mathrm{~ms}$. Hence the inference from this image is that this part of the wetland has a particularly clay rich pro- file, the full length of the wetland, contrasting with the larger arm of the wetland seen in Figs. 9 and 10. Of particular note in Fig. 10 is the very high capacitance $(<0.01 \mathrm{~ms})$ material seen from the point of origin to $\sim 25 \mathrm{~m}$. This material corresponds with the vertical band of material seen near the origin in Fig. 9. Furthermore, one observes a vertical band of high capacitance material $(<0.01 \mathrm{~ms})$ at $\sim 30 \mathrm{~m}$ extending from the surface to $5 \mathrm{~m}$ deep. However, despite the inversion of the data using a robust method with optimized damping factors, the pseudosection was achieved with a relatively high root mean square (RMS) error, and hence this image must be interpreted with caution. Meanwhile, the satisfactory inversion of the corresponding resistivity image for this section aids in the interpretation of this anomalous IP output. This resistivity data is displayed in Fig. 12, where one observes a lateral stratification of the sub-surface media within this profile, particularly a band of material of $<1000 \Omega$ m between 693-698 $\mathrm{m}$ a.s.1., similarly this banding is also discernable in Fig. 10 for the complementary transect in the alternative orientation. In both cases this low resistivity/high capacitance material overlies a slightly higher resistance material at depth (note the material under-arch in Fig. 10). Moreover, in Fig. 11 one observes the slight reduction in material capacitance below $697 \mathrm{~m}$ a.s.l., beyond $30 \mathrm{~m}$. However, Fig. 12 does reveal the anomalous nature of the vertical band of high capacitance material at $30 \mathrm{~m}$ seen in Fig. 11, which does not tally with the higher resistant material observed at this location in the resistivity profile. One possible reason for this anomaly, speculatively speaking, may be due to the presence of cracked clay in the profile, which due to the dry winter period at the time of surveying is highly likely. Therefore, although the clays themselves will have high capacitance, if they are cracked and hence have very large inter-pore spaces may engender large resistivity readings due to greater air to pore ratios in the soil medium than under wetter conditions.

The results of IP surveys using the gridded 21 electrode method at the wetland footslope interface revealed the highly variable nature of the material here in terms of its chargeability. Figure 13 displays this data in two orientations around the origin. This variability is reflected in the stratification of chargeability layers and heterogeneities in the near surface. It must be remembered here that due to the short electrode array and short spacing of these electrodes the vertical depth penetration is reduced, and hence the resulting survey provides a resolution to a depth of $3 \mathrm{~m}$. Nevertheless the resulting output reveals the patchy network of low capacitance ( $>6 \mathrm{~ms}$ ) material near the surface and this reflects the disturbed material at the wetland surface that has been mechanically altered to create raised bed and furrow systems used for cultivation purposes. Meanwhile, one is able to discern that this unconsolidated material overlies a deeper layer of rather high capacitance material $(<1 \mathrm{~ms})$, which varies in its depth across the $15 \mathrm{~m} \times 15 \mathrm{~m}$ domain.

Figure 14 displays the same data, except that an IP filter has been applied to display chargeability data only below 


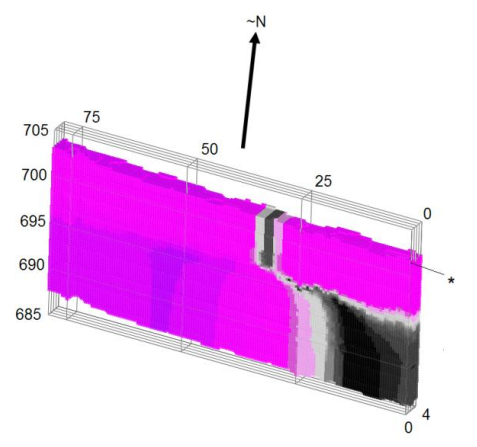

"origin: $30.97541,-24.66747$

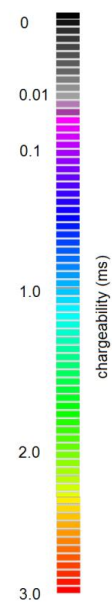

Fig. 11. Pseudo 3-D IP section of the SW-NE parallel transects. Scales are in metres diverging from a geographical origin, vertical scale is altitude a.s.l. (Wenner long, $2 \mathrm{~m}$ spacing, 6th iteration, RMS error $13.3 \%$ ).

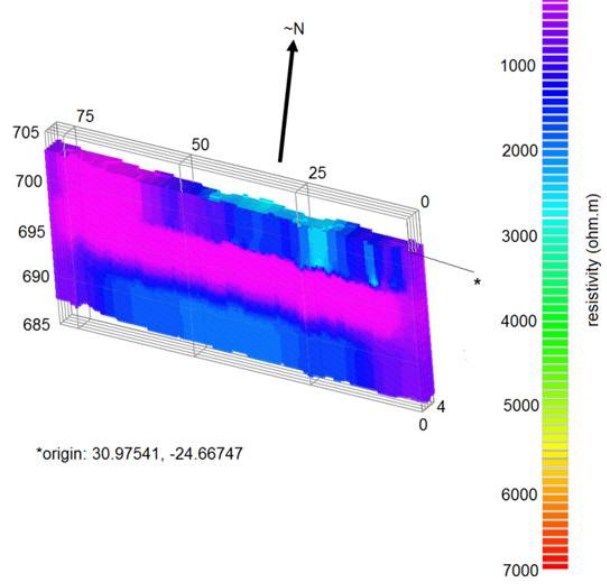

Fig. 12. Pseudo 3-D resistivity section of the SW-NE parallel transects. Scales are in metres diverging from a geographical origin, vertical scale is altitude a.s.l. (Wenner long, $2 \mathrm{~m}$ spacing, 6th iteration, RMS error $5.92 \%$ ).

$1 \mathrm{~ms}$, which in essence allows for visual representation of only the high capacitance material at the wetland-footslope interface. The resulting pseudosection reveals that although this high capacitance material is somewhat laminar there is an obvious increase in depth to this layer with increasing distance from the point of departure of the grid from the origin. With this origin being at the wetland-footslope interface, one is therefore able to note that this material is protruding from the hillside into the valley bottom, with a descent in the $\mathrm{N}$, $\mathrm{NE}$ and $\mathrm{E}$ direction.

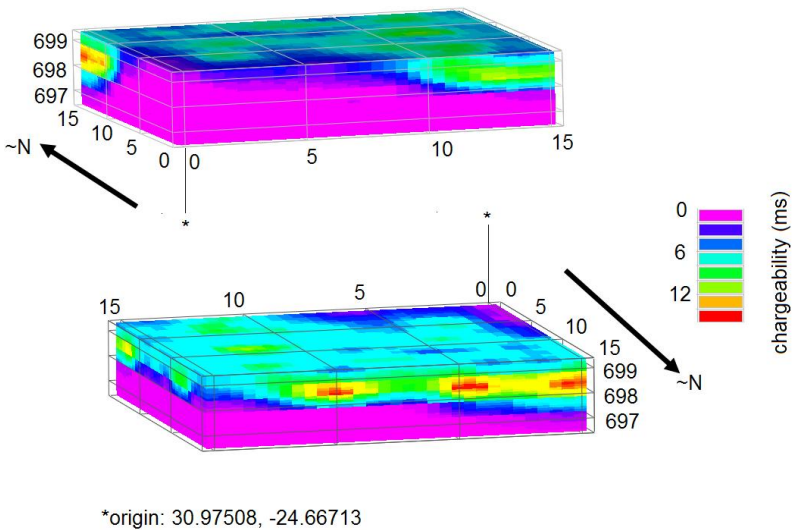

Fig. 13. Pseudo 3-D (with improved XY resolution) IP section of the wetland-footslope interface. Scales are in metres diverging from a geographical origin, vertical scale is altitude a.s.l. (Wenner$\beta \times 21$, 4th iteration, RMS error $3.35 \%$ )

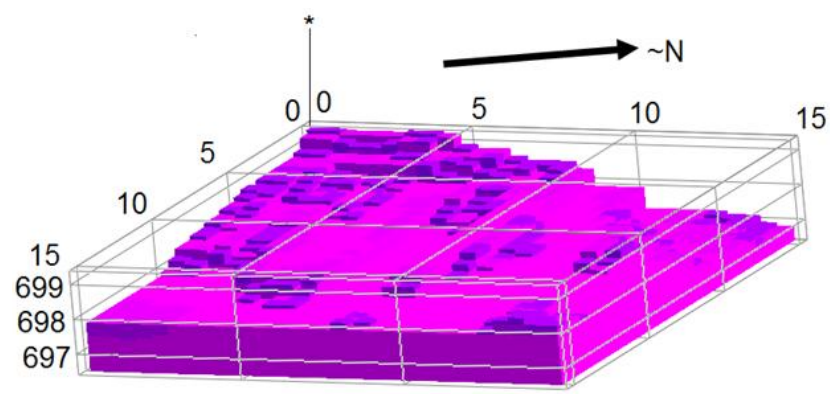

*origin: $30.97508,-24.66713$

Fig. 14. Pseudo 3-D IP section of the wetland-footslope interface with chargeability values filtered to between $0-1 \mathrm{~ms}$. Scales are in metres diverging from a geographical origin, vertical scale is altitude a.s.l.

\subsection{Verification}

In order to verify the output of the IP profiles, whose characteristically high capacitance regions suggest the occurrence of clays, a rapid and random series of auger holes were dug to a depth where clay was observed and defined through a bolus test. The locations of the random augered ground truthing points in relation to the parallel transects are displayed in Fig. 15. Furthermore, Fig. 15 also displays an image of the face of the actively eroding gully headcut (wet season March 2006), whereupon the saturation of the soil profile reveals two distinct horizons within the wetland substrate, a shallow sandy loam horizon above a deep fine clay horizon. Since the SE-NW transect (Fig. 9) shows that from the point of origin to approximately $50 \mathrm{~m}$ the wetland is made up of a high capacitance material $(<1 \mathrm{~ms})$ and this is relatively consistent from the surface throughout the entire depth of the profile. The fact that clays were encountered within $1 \mathrm{~m}$ of 


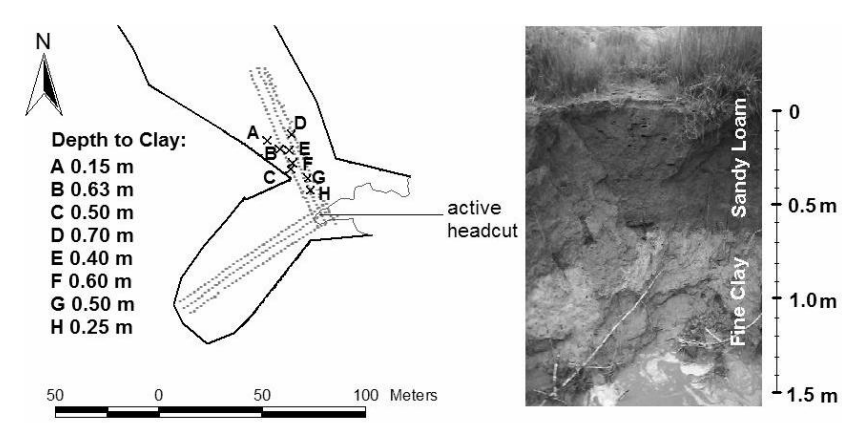

Fig. 15. Locations of auger sample points to clay horizons $(L)$ and discernable shallow sandy loam soils over lying deep fine clays of the Kroonstad (Planosol) soil form exposed at the site of active gullying $(R)$.

the wetland surface at these locations support the inferences made about clay distribution from the IP surveys.

An analysis was also undertaken to verify IP interpretations by using measures of saturated conductivity $(K)$ at the hydrometric monitoring stations. This verification is considered semi-quantitative since, as will become apparent, repeated bail tests could not be undertaken due to the extremely slow recoveries of the piezometers. Hence, the displayed $K$ values of Fig. 16 are single measurements and therefore treated as estimates of $K$ at the various piezometer depths. Figure 16 displays the closest measured IP (ms) and apparent resistivity $(\Omega \mathrm{m})$ value at each depth corresponding to the depth of the piezometer well at each hydrometric monitoring location (Fig. 2). These values originate from the raw 4 point resitivity measurements rather than from the inverted pseudosections. In cases where $K$ was determined at depths $>2 \mathrm{~m}$, the $K$ is extremely low, implying that water levels in the wells would take hours if not days to recover to equilibrium levels prior to conducting bail tests.

When resistivity data is plotted against $\log$ values of $K$ there appears to be good agreement between the estimated conductivity of the material at the respective piezometer depths and the measured apparent resistivity of the same material for all wells (note there is only one well at H11). However the correlation coefficient for $\log K$ against chargeability at 0.65 is much more agreeable than against resistivity at -0.45 . In each case however the plots appear to show a decline in resistance (or increased conductance) with $K$ at depth, which tapers off below a depth of $4 \mathrm{~m}$. The situation with the IP data does not yield the same clear relationship, although trends may be observed. Firstly, there is a general decrease in $K$ of the wetland material whilst capacitance increases (chargeability time decreases), up to $4 \mathrm{~m}$ depth. Second, at depths beyond $4 \mathrm{~m} K$ increases slightly at piezometer locations $\mathrm{H} 7$ and $\mathrm{H} 8$, and at $\mathrm{H} 11$ capacitance and $K$ tally. Therefore, there is a trend between these two variables of $K$ and chargeability, however the clarity of their relationship is concealed by the very small chargeabil-
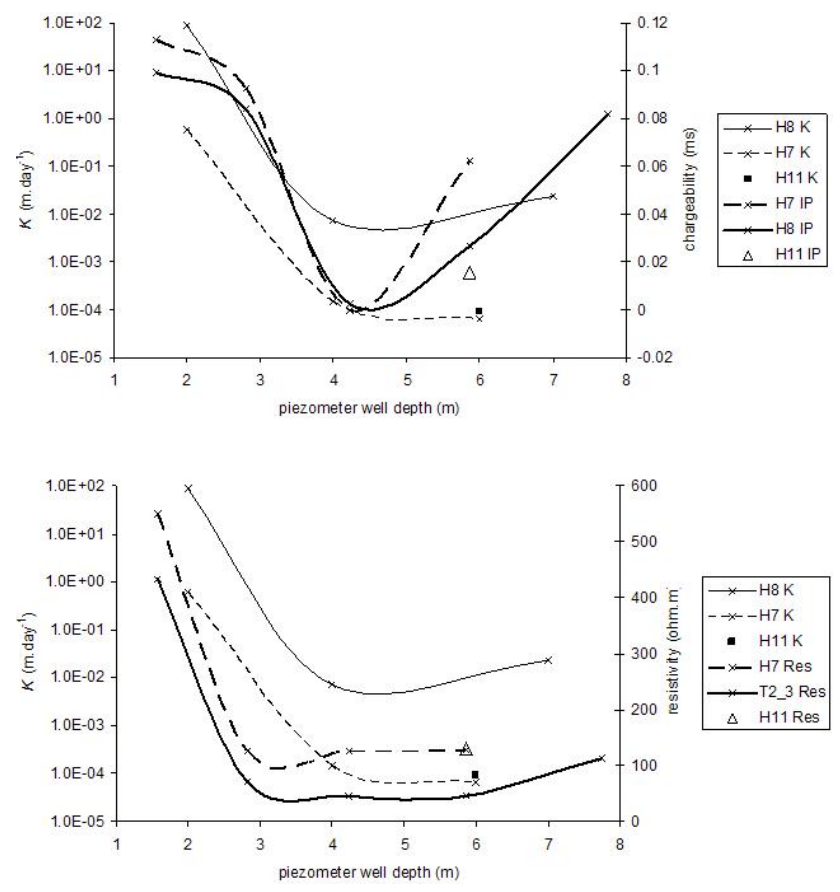

Fig. 16. Plots of $\log -K$ vs. IP measurements (above) and resistivity measurements (below).

ity range that is plotted on the secondary Y-axis. Obviously, more repeated $K$ tests and precise determination of resistivity and chargeability would be ideal in order to verify the ERI and IP output. However this was negated by conditions in the field i.e. very low conductivities, and output of measured apparent resistivities, where the readings extracted from inversion-model output would not have been in precisely the same location as the piezometer wells.

\section{Discussion}

The addition of 3-D combined IP and resistivity surveys to the 2-D scoping surveys and supporting hydrometry data have allowed a real insight into the hydro-geomorphic controls within this wetland system and facilitated a proposed model for the development of these controls, particularly in terms of clay-plug formation. The rationale for the proposed model will now be outlined:

Remembering that the SE-NW orientated parallel transects (Figs. 9 and 10) situated in a larger region of the wetland (refer to Fig. 2) show that the chargeability time in the wetlands sub-surface increases with distance NW away from the origin. Meanwhile the SW-NE orientated transects within the smaller wetland region displays an extremely high capacitance all the way along this part of the wetland. This provides for the first point of interest. The suggestion is that the smaller wetland region has a more uniform clay distribution in the sub-surface than the larger region, and the latter 
therefore is likely comprised of increasingly coarser (higher resistance, lower capacitance) material away from the juncture of these two regions (tributaries) of the wetland. Furthermore, it was noted that there was a distinct down sloping of higher capacitance material with distance away from the hillslope-wetland interface. These two observations facilitate the notion that finer (clay) particles are removed from the hillslope units through the process of elluviation, which is a common process on these geological terrains in semiarid settings, particularly in the case of clay enriched sodic sites of the region (e.g. Khomo and Rogers, 2005). This elluviation allows for their deposition (or illuviation) as distinct clay rich horizons at the hillslope toes, which in this catchment have been described according to the South African soil taxonomic system as a Kroonstad soil form (Soil Classification Working Group, 1991). Clay rich illuviated horizons are termed "G-horizons" according to the South African definition. These soils translate to the World Reference Base (FAO, 1998) system as planosols. This illuviation process has probably been more concentrated within the smaller wetland region due to the higher capacitance and more uniform distribution of this material within this region. This has effectively created a barrier across the confluence with the larger wetland region. Furthermore, the confinement zone or valley pinches that are observed at this confluence has also contributed to this barrier creation, and one observes this process when interpreting Figs. 9 and 11 to their respective positions at this confluence. Indeed the arch-like structure obvious in Fig. 9 suggests an extremely dense clay formation (clayplug) that could have been created by two (or more) illuvial pathways at this juncture. Effectively what this scenario creates is a zone of infilling by coarser clastic sediments into the larger wetland region from the broader contributing catchment. Indeed the soil types in this larger region of the wetland have been described as hydromorphic soils of the Katspruit form, which accordingly translate to gleysols (FAO, 1998) which typically develop under wet conditions in unconsolidated materials.

This pedological evidence lends credence to a hypothesis proposed here that valley bottom (wetland) infilling, by unconsolidated colluvial and alluvial material, has occurred behind these clay-plugs. This proposed model therefore implies that there is a lateral as well as vertical removal of finer materials in the slopes of these wetland catchments and their concentration at zones of valley confinement. The proposed model is depicted schematically in Fig. 17 and photographically in Fig. 18.

Based on the observations and measurements presented in this manuscript, it is known that the Manalana wetland is underlain by a deep clay material $(>4 \mathrm{~m}$ ) with a moderate hydraulic conductivity in relation to an overlying dense clay with extremely low hydraulic conductivity (somewhere between $4 \mathrm{~m}-2 \mathrm{~m}$ ). At considerable depth, certainly beyond $6 \mathrm{~m}$ the wetland is bounded by bedrock and saprolitic material. It is also known that the clays have a particularly high density at the confluence of the two arms of the wetland, adjacent to the clay-plug. In addition, the near sub-surface of the wetland is largely a sandy horizon with high hydraulic conductivity, and in the smaller arm (SW-NE) of the wetland this horizon is very shallow such that this section is predominantly underlain by clay material, that through lateral illuvial processes, and illuviation of clays from the hillslope at valley constriction (see Fig. 18) has effectively created an illuvial barrier across the confluence with the larger wetland region (SE-NW). Furthermore, as one moves upstream along the larger wetland region, material becomes less consolidated giving way to a deeper sandy matrix.

Understanding of climatically induced evolution of wetlands in southern Africa is outlined in Ellery et al. (2008), as being intimately linked with glacial and interglacial periods of erosion dominated cycles attributed to the warmer and wetter conditions of the latter, and deposition dominated dryer cycles of the former. Furthermore, the clarity of erosion terraces seen within the Manalana catchment reveal that this is indeed the case and the process of cut-and-fill valley evolution in the Manalana has been discussed by Ellery and Kotze (2008), and this reciprocates the findings discussed here, as valley bottom in-filling is noted through our interpretations presented here.

Given the fact that the Manalana represents one of many sub-catchments at the Sand Rivers headwaters which are all in a similar state of degradation the identification of hydro-geomorphic buffers/barriers, such as clay-plugs is crucial. This relates to the concept of catchment connectivity. Whereby, the connectivity of process domains from coupled hillslope-valley bottom wetlands and longitudinal throughwetland processes, as in the case of Manalana catchment and others, are increasing significantly due to degradation process such as erosion gullying. This relates to a concept described by Fryirs et al. (2006) where, the identification and understanding of the hydro-geomorphic processes that buffers/barriers (be they rock outcrops or differential sediment depositions) facilitate in terms of switching on or off these coupled processes within a fluvial network, is important for their successful management. Therefore in light of the already determined hydraulic function that the sub-surface clay-plugs have in terms of ameliorating lateral throughflows in the wetland, and the possible identification of hydro-geomorphic process zones that engender the development of these clay-plug buffers, one should now be able to identify zones within these catchments where they are likely to occur (cryptically). This therefore provides a means to protect these zones, in the absence of access to technical geophysical equipment, one proposes that to reveal and delineate the location of these clay-plugs, identification of regions of valley constriction be made, which may then be analyzed qualitatively through in-situ soil analysis for their clay content. 


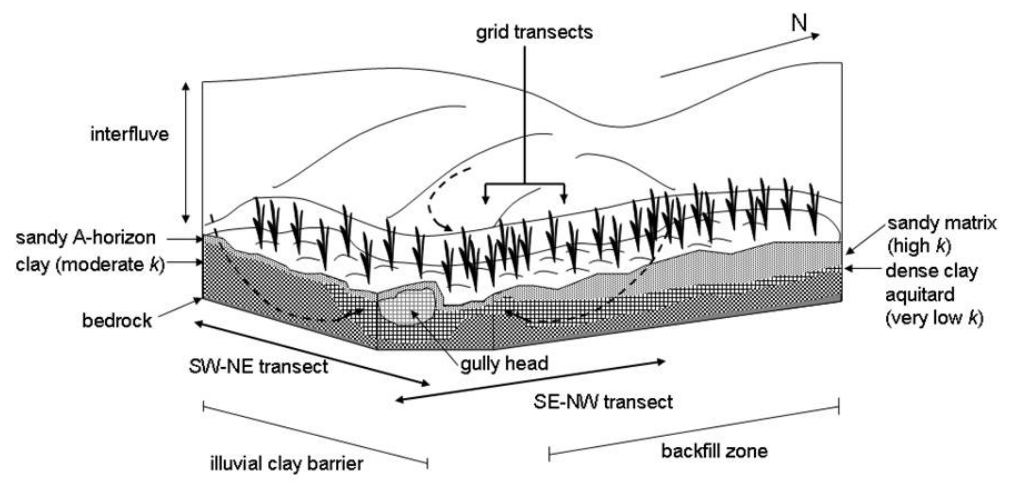

'... arrows indicating direction of valley confinement and illuviation

Fig. 17. Schematic of conceptual model for clay-plug development in the Manalana wetland (not to scale).

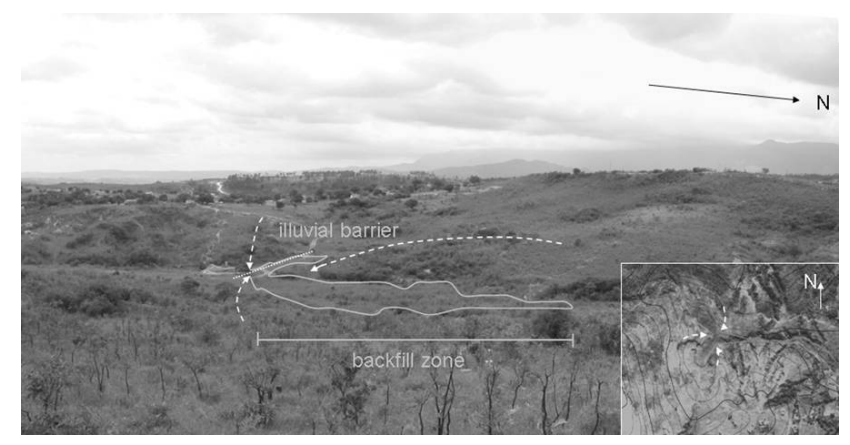

Fig. 18. South facing view of the Manalana wetland (solid line) with proposed model for clay-plug development highlighting hillslope confinement zones and illuviation pathways (dashed line) and illuvial barrier (dotted line). Inset represent aerial view of hillslope confinement zones.

Beauvais et al. (1999) successfully used ERI to describe hydro-geomorphic processes on other granitic terrains in Senegal by identifying both mechanical and weathering induced drivers of hillslope geomorphology. The ERI approach here using additionally, IP, has similarly assisted in the development of a conceptual model for the evolution of hydrogeomorphic controls in the wetlands of the Sand River system. However it is interesting to note that even in a relatively recent sedimentology study (Baines et al., 2002) making use of similar technology highlighted the lack of a due procedure to be followed when undertaking such geophysical surveys for geomorphic understanding. Given that there are a variety of sources of uncertainty in ERI such as the evenness of electrode spacing (e.g. Oldenborger et al., 2005), not accounting for variations in moisture of the substrate, or even the misappropriation of the correct resitivity range for the geological area in question, highlights the importance of ground truthing of ones geophysical data as far as is possible. Despite these sources of uncertainty Baines et al.(2002) and Loke (1999) advocate the use of qualitative ground truthing to verify geo- physical interpretations, and the verification approaches used in this study were highly valuable in this respect. This is an issue that should be developed and refined in the future, particularly where the use of geophysical methods for low cost rapid hydro-geomorphic interpretation (outside of the fields of geological and mineral prospecting for instance) of wetlands and other landscape units is required. It is therefore advocated here that the combined use of ERI and IP be used, were possible, in cases such as wetland rehabilitation planning. This is particularly pertinent to South Africa, a water scarce country, where wetland rehabilitation is common place and where hydrological and geomorphological data relating to the wetland is often lacking. Moreover, it is widely accepted that these geophysical approaches add huge value to understanding hydrological process data in research catchments, in which they aid in the extrapolation of point measurements to the larger scale (Wenninger et al., 2008). Hence the data discussed here will be of real benefit for the development of a hydrological process model of the Manalana wetland and its sister catchments in the future.

\section{Conclusions}

The use of the geophysical methods of ERI and IP have shown their suitability for describing hydro-geomorphic structures within wetland catchments. In particular these relatively rapid approaches are envisaged to have application in the future for extrapolating hydrological regimes and hydrogeomorphic controls in wetland systems, this has important hydro-ecological and economic implications for the plethora of wetland (and river) rehabilitation projects now underway in South Africa where robust conceptual models of these wetland processes are required to facilitate appropriate and successful rehabilitation measures. In this regard the use of this approach allowed for the identification of crucial geomorphic processes that control catchment connectivity in this region. In particular the surveys allowed for the delineation 
of clay-plug sub-surface hydrological buffers and provided information on their modes of formation, albeit by inferring where they will likely occur with respect to longitudinal valley position. The findings will now enable the future protection of these zones from externally derived degradation processes and it is envisaged that this methodology be suitably applied in the future, particularly for wetland rehabilitation planning.

Acknowledgements. The authors are grateful to the South African Water Research Commission (WRC) and National Research Foundation (NRF) for financial support. Professor Fred Ellery (Rhodes University) for assistance with geomorphic concepts and facilitating the initial wetland monitoring project. The kind assistance of the following people for field assistance, data processing and interpretation is duly acknowledged; Johannes Hachman (University of Freiburg), Bertram Koning (University of KwaZuluNatal). Pieter Le Roux and his team (University of Free State) for assistance in data collection and in interpretation of soil form characteristics. Logistical and administrative support was provided by the Association for Water and Rural Development (AWARD).

Edited by: E. Zehe

\section{References}

Acocks, J. P. H.: Veld Types of South Africa, Memoirs of the Botanical Survey of South Africa, Botanical Research Institute, Dept. of Agriculture and Water Supply (South Africa), 57, 146 pp., 1988.

Baines, D., Smith, D. G., Froese, D. G., Bauman, P., and Nimeck, G.: Electrical resistivity ground imaging (ERGI): a new tool for mapping the lithology and geometry of channel-belts and valleyfills, Sedimentology, 49, 441-449, 2002.

Beauvais, A., Ritz, M., Parisot, J. C., Dukhan, M., and Bantsimba, C.: Analysis of poorly stratified lateritic terrains overlying a granitic bedrock in West Africa, using 2-D electrical resistivity tomography, Earth Planet. Sc. Lett., 173, 413-424, 1999.

Beauvais, A., Parisot, J. C., and Savin, C.: Ultramafic rock weathering and slope erosion processes in a South West Pacific tropical environment, Geomorphology, 83, 1-13, 2007.

Bouwer, H. and Rice, R. C.: A slug test for determining hydraulic conductivity of unconfined aquifers with completely or partially penetrating wells, Water Resour. Res., 12(1), 423-428, 1976.

Dahlin, T.: 2-D resistivity surveying for environmental and engineering applications, First Break, 14(7), 275-283, 1996.

Ellery, W. N. and Kotze, D. C.: WET-OutcomeEvaluate, in: WETManagement, The Wetland Management Series, 11 Chapters, edited by: Breen, C., Dini, J., Mitchell, S., and Uys, M., Water Research Commission, Gezina, Pretoria, WRC Report No. TT 343/08, 2008.

Ellery, W. N., Grenfell, M., Grenfell, S., Kotze, D. C., McCarthy, T. S., Tooth, S., Grundling P. L., Beckedahl, H., Le Maitre, D., and Ramsay L.: WET-Origins, Controls on the distribution and dynamics of wetlands in South Africa, in: WET-Management, The Wetland Management Series, 11 Chapters, edited by: Breen, C., Dini, J., Mitchell, S., and Uys, M., Water Research Commission, Gezina, Pretoria, WRC Report No. TT-334, 2008.
FAO 1998.: World Reference Base for Soil Resources, Rome Food and Agriculure Organization of the United Nations FAO, International Society of Soil Science ISSS-AISS-IBG, International Soil Reference Group, available at: http://www.fao.org/ag/agl/ agll/wrb/newkey.stm, last access: January 2010.

Fryirs, K. A., Brierley, G. J., Preston, N. J., and Kasai, M.: Buffers, barriers and blankets: The (dis)connectivity of catchment-scale sediment cascades, Catena, 70(1), 49-67, 2006.

Khomo, L. M. and Rogers, K. H.: Proposed mechanism for the origin of sodic patches in Kruger National Park, South Africa, Afr. J. Ecol., 43, 29-34, 2005.

Kiberu, J.: Induced polarization and Resistivity measurements on a suite of near surface soil samples and their empirical relationship to selected measured engineering parameters, Interntional Institute for Geo-information Science and Earth Observation, Enschede, The Netherlands, availabel at: http://www.itc. nl/library/Papers/msc_2002/ereg/kiberu.pdf, (last acces: March 2009), 2002.

Kneisel, C.: Assessment of subsurface lithology in mountain environments using 2-D resistivity imaging, Geomorphology, 80, 32-44, 2006.

Kohler, M. A. and Linsley, R. K.: Predicting the runoff from storm rainfall. Weather Bureau, US Department of Commerce, Washington, Research Paper No. 34, p. 9, 1951.

Kunz, R.: Daily Rainfall Data Extraction Utility, User Manual v. 1.0, Institute for Commercial Forestry Research, Pietermaritzburg, Republic of South Africa, 2004.

Loke, M. H.: Electrical imaging surveys for environmental and engineering studies: A practical guide to 2-D and 3-D surveys, available at: www.terrajp.co.jp/lokenote.pdf, (last acces: August 2008), 1999.

Loke, M. H.: Tutorial: 2-D and 3-D electrical imaging surveys, available at: www.geoelectrical.com, (last acces: August 2008), 2004.

Loke, M. H.: Res2dinv 2-D Resisitivity and IP inversion, Geotomo Software, Malaysia, available at: www.geoelectrical.com, (last access: August 2008), 2005a.

Loke, M. H.: Res3dinv 3-D Resistivity and IP Inversion, Geotomo Software, Malaysia, available at: www.geoelectrical.com, (last access: August 2008), 2005b.

Lowrie, W.: Fundamentals of Geophysics, Second Edition, Cambridge University Press, ISBN-13, 9780521859028, 2007.

Marescot, L., Monnet, R., and Chapellier, D.: Resistivity and induced polarization surveys for slope instability studies in the Swiss Alps, Eng. Geol., 98(1-2), 18-28, 2008.

Oldenborger, G. A., Routh, P. S., and Knoll, M. D.: Sensitivity of electrical resistivity tomography data to electrode position errors, Geophys. J. Int., 163, 1-9, 2005.

Pollard, S., Kotze, D., Ellery, W., Cousins, T., Monareng, J., King, K., and Jewitt, G.: Linking Water and Livelihoods The development of an integrated wetland rehabilitation plan in the communal areas of the Sand River Catchment as a test case, Association for Water and Rural Development Warfsa/Working for Wetlands, AWARD internal report, 2005.

Riddell, E. S., Lorentz, S. A., Ellery, W. N., Kotze, D., Pretorius J. J., and Nketar, S. N.: Water Table Dynamics of a Severely Eroded Wetland System, Prior to Rehabilitation, Sand River Catchment, South Africa, Proceedings of the XXXV IAH Congress on Groundwater and Ecosystems, 17-21 September, Lisbon, Portu- 
gal, 2007.

Riddell, E. S and Lorentz, S. A.: Hydrologic mechanisms in a granitic hillslope that induce rapid phreatic surface responses in a headwater wetland, in review, 2010.

Robinson, D. A., Binley, A., Crook, N., Day-Lewis, F. D., Ferré, T. P. A., Grauch, V. J. S., Knight, R., Knoll, M., Lakshmi, V., Miller, R., Nyquist, J., Pellerin, L., Singha, K., and Slater, L.: Advancing process-based watershed hydrological research using near-surface geophysics: a vision for, and review of, electrical and magnetic geophysical methods, Hydrol. Process., 22, 36043635, 2008.

Ruhe, R.: Elements of the soil landscape, Trans. 7th Intl. Congr. Soil Sci., Madison, WI, 4, 165-170, 1960.

Schaetzl, R., and Anderson, S. (Eds.): Soils: Genesis and Geomorphology, Cambridge, UK, Cambridge University Press, ISBN978-0-521-81201-6, 2005.

Sharma, P. V.: Environmental and Engineering Geophysics, Cambridge University Press, ISBN-978-0521576321, 2008.

Slater, L. D. and Lesmes, D.: IP interpretation in environmental investigations, Geophysics, 67(1), 77-88, doi:10.1190/1.1451353, 2002.

Slater, L. D. and Reeve, A.: Investigating peatland stratigraphy and hyderogeology using integrated electrical geophsics., Geophysics, 67(2), 365-378, doi:10.1190/1.1468597, 2002.
Smith, R. C. and Sjorgen, D. B.: An evaluation of electrical resistivity imaging (ERI) in Quaternary sediments, southern Alberta, Canada, Geosphere, 2(6), 287-298, 2006.

Soil Classification Working Group, Soil classification a taxonomic system for South Africa, Memoirs on the Agricultural Natural Resources of South Africa Ed., Memoirs on the Agricultural Natural Resources of South Africa No. 15., SIRI, D.A.T.S., Pretoria, 1991.

Tongway, D. J. and Hindley, N. L. (eds.): Landscape Function Analysis: Procedures for monitoring and assessing landscapes, CSIRO Australia, ISBN-0-9751783-0-X, 2004.

Tooth, S. and McCarthy, T. S.: Wetlands in drylands: geomorphological and sedimentological characteristics, with emphasis on examples from Southern Africa, Prog. Phys. Geog. 31(1), 3-41, 2007.

Uhlenbrook, S., Wenninger, J., and Lorentz, S.: What happens after the catchment caught the storm? Hydrological processes at the small, semi-arid Weatherley catchment, South-Africa, Adv. Geosci., 2, 237-241, doi:10.5194/adgeo-2-237-2005, 2005.

Wenninger, J., Uhlenbrook, S., Lorentz, S., and Leibundgut, C.: Identification of runoff generation processes using combined hydrometric, tracer and geophysical methods in a headwater catchment in South Africa, Hydrolog. Sci. J., 53(1), 65-80, 2008. 